Article

\title{
Collection and Integration of Local Knowledge and Experience through a Collective Spatial Analysis
}

\author{
Juan Daniel Castillo-Rosas ${ }^{1,2, *}$, José José Diez-Rodríguez ${ }^{3}$, Alex Fernando Jiménez-Vélez ${ }^{1,4}$, \\ María Amparo Núñez-Andrés ${ }^{5}$ and Josep María Monguet-Fierro ${ }^{1}$ \\ 1 Departament d'Expressió Gràfica a l'Enginyeria, Universitat Politècnica de Catalunya (UPC-BarcelonaTech), \\ Av. Diagonal, 647, 08028 Barcelona, Spain; afjimenezv@gmail.com (A.F.J.-V.); \\ jm.monguet@upc.edu (J.M.M.-F.) \\ 2 Dirección General de Cartografía, SEDENA, Av. Industria Militar, 261, 53960 Naucalpan, Mexico \\ 3 Departament de Projectes d'Enginyeria, Universitat Politècnica de Catalunya (UPC-BarcelonaTech), \\ Av. Diagonal, 647, 08028 Barcelona, Spain; jose.jose.diez@estudiant.upc.edu \\ 4 Departamento de Ciencias de la Computación, Universidad de las Fuerzas Armadas (ESPE), \\ Av. Gral. Rumiñahui s/n, 170501 Sangolquí, Ecuador \\ 5 Departament d'Enginyeria del Terreny, Cartogràfica i Geofísica, Universitat Politècnica de Catalunya \\ (UPC-BarcelonaTech), Av. Doctor Marañon, 44-50, 08028 Barcelona, Spain; m.amparo.nunez@upc.edu \\ * Correspondence: jdcastillo@unam.mx; Tel.: +52-55-2122-8800 (ext. 3160)
}

Academic Editors: Shih-Lung Shaw, Qingquan Li, Yang Yue and Wolfgang Kainz

Received: 28 October 2016; Accepted: 18 January 2017; Published: 24 January 2017

\begin{abstract}
This article discusses the convenience of adopting an approach of Collective Spatial Analysis in the P/PGIS processes, with the aim of improving the collection and integration of knowledge and local expertise in decision-making, mainly in the fields of planning and adopting territorial policies. Based on empirical evidence, as a result of the review of scientific articles from the Web of Science database, in which it is displayed how the knowledge and experience of people involved in decision-making supported by P/PGIS are collected and used, a prototype of a WEB-GSDSS application has been developed. This prototype allows a group of people to participate anonymously, in an asynchronous and distributed way, in a decision-making process to locate goods, services, or events through the convergence of their views. Via this application, two case studies for planning services in districts of Ecuador and Italy were carried out. Early results suggest that in $\mathrm{P} / \mathrm{PGIS}$ local and external actors contribute their knowledge and experience to generate information that afterwards is integrated and analysed in the decision-making process. On the other hand, in a Collective Spatial Analysis, these actors analyse and generate information in conjunction with their knowledge and experience during the process of decision-making. We conclude that, although the Collective Spatial Analysis approach presented is in a subjective and initial stage, it does drive improvements in the collection and integration of knowledge and local experience, foremost among them is an interdisciplinary geo-consensus.
\end{abstract}

Keywords: PGIS; PPGIS; SDSS; SIGIC; spatial decision-making; geo-consensus; Collective Spatial Analysis

\section{Introduction}

A vital body of research on Public Participation Geographic Information Systems and Participatory Geographic Information Systems (P/PGIS) has been extensively developed as a consequence of the use of Web-mapping and spatial analysis in the participatory planning and adoption of territorial policies processes. This is for the reason that community-planning agreements with matters that have implicit or explicit geographical dimensions, maps, and GIS are frequently used to assist discussion. 
P/PGIS applications, which involve relevant stakeholders, including citizens, developers, interest groups, and government officials, are recognised as discovering consensual clarifications to given encounters by inspiring and endorsing informed citizen participation in policy formulation and territorial planning [1-3]. The aggregated essential information and the obtainability of geospatial data on the Internet make Web-based P/PGIS applications more and more widespread [4,5].

On the other hand, the core values of the International Association for Public Participation [6], state that public participation must involve the affected people with some kind of "consultation", "participation" or "collaboration" in the decision-making process. However, this process for the purpose of planning and adopting territorial policies is a complex one that requires the best alternatives from all possible perspectives, especially the participation and consensus of the involved stakeholders [1,3] An understanding of this work as a consensus, "an idea associated with the decision-making process and the common-agreement building among most of the participants of an organisation or a community" [7], is particularly useful "for systems in which uncertainty of information is assumed but the decision making process is required" [8].

For this purpose, in recent years, the use of P/PGIS has been favored as a useful tool for the inclusion, democratisation, and empowerment of the communities in the plans for local development. However, there is little evidence that the data collected through these technologies is used for the decision-making process [9], being mainly used instead to identify social problems and integrate the objectives of the planning with the preferences and social values for development [10], and so there is no evidence concerning the use of P/PGIS as a consensus mechanism among the involved stakeholders in the decision-making process.

In the decision-making process for planning and territory policies, it is usually required that the data collected from the involved stakeholders is first integrated and then processed through a method of spatial analysis, a concept closely linked with computer geoprocessing of geospatial data, specially through Geographical Information Systems [11]. Nonetheless, it is necessary at this point to specify the following two aspects. First, the spatial analysis can also be carried out through other means, either by visual and interactive interpretation of data (georeferenced or not) using measuring and recording instruments, or through straight perception and interpretation of the environment. Secondly, in all types of spatial analysis without exception, the knowledge, experience, and judgment of the one conducting the spatial analysis play a key role.

In the same line of thinking, thanks to the evolution of the Web 2.0 and aligned with the philosophy of collective intelligence, Collective Spatial Analysis aims to generate spatiotemporal locations from the consensus or convergence of opinions from a group of experts, whose conclusions, assumptions, or solutions contribute knowledge and experiences to answering questions that help to explore, describe, explain, or predict characteristics or properties of the complexity of the geographical space from multiple cognitive perspectives, experiences, and criteria [12].

The term Collective Intelligence, for the purpose of this work, should be understood as "the capacity of human collectives to engage in intellectual cooperation in order to create, innovate and invent" [13]. This is a property that results from the arising of synergies between data, information, knowledge, software, hardware, and a group of people, who learn from and contribute to the knowledge of the group in the search for the best alternatives to a given situation [14].

Therefore, this research presents an empirical assessment of the usability of a Web-GSDSS application called the Geospatial System of Collective Intelligence, which allows a group of people to participate anonymously, in an asynchronous and distributed way, in a decision-making process to locate goods, services, or events through the convergence of their views. Early results suggest that in P/PGIS local and external stakeholders contribute their knowledge and experience to generate information, which is afterwards integrated and analyzed in a decision-making process; whereas, in a Collective Spatial Analysis, these actors analyse and generate information in conjunction with their knowledge and experience during the process of decision-making. 


\section{Materials and Methods}

\subsection{Literature Review}

In order to identify how it has been collected and used so far, the knowledge and experience of people in support of decision-making in P/PGIS, a thorough review of scientific articles was undertaken, mainly those in the Web of Science database. From these, a study by Brown and Fagerholm [9] stands out, in which the review of 32 articles with empirical evidence was compiled to determine the current and best practices in the use of P/PGIS. Therefore, this is taken as a baseline to which an update of 7 more articles is added and shown in Table 1, which adds up to a total of 39 peer reviewed scientific articles from 1998 to 2015 that describe the sampling, data collection, and spatial analysis methods used, among other aspects.

From the 39 reviewed cases, and just as authors Brown \& Fagerholm [9] state, there is little empirical evidence about the use of data collected through P/PGIS to support decision-making in planning (6 cases), and from these only in one of them was the data collection built up and local experience taken into account during the decision-making process, albeit in a hypothetical way [3].

In this case, a Web application was presented which allowed the participants to achieve a consensus in real time during the decision-making process by using the multicriteria decision analysis (MCDA) to make a selection from among the predefined polygons and through the scorings that the group provided about a set of alternatives presented.

It is worth mentioning that in a different case study a similar process was implemented, where in the stakeholders debated their opinions in workshops that were monitored by the researchers. These aimed at reaching a consensus about the selection of locations in a zone of study that was displayed on a screen. The opinions about spatial locations of the participants were recorded in a GIS that updated the screen at all times as feedback was provided by the group; however, the final goal of that work was not to support the decision-making process but to determine how the processes and outcomes of the P/PGIS made an impact on empowerment [2].

A prototype of a WEB Group Spatial Decision Support System (Web-GSDSS) application was developed (Figure 1), to which a function was added to automate the spatial version of the Delphi method [15,16], in combination with the Delphi method in real-time [17-20] and the Vector Consensus.

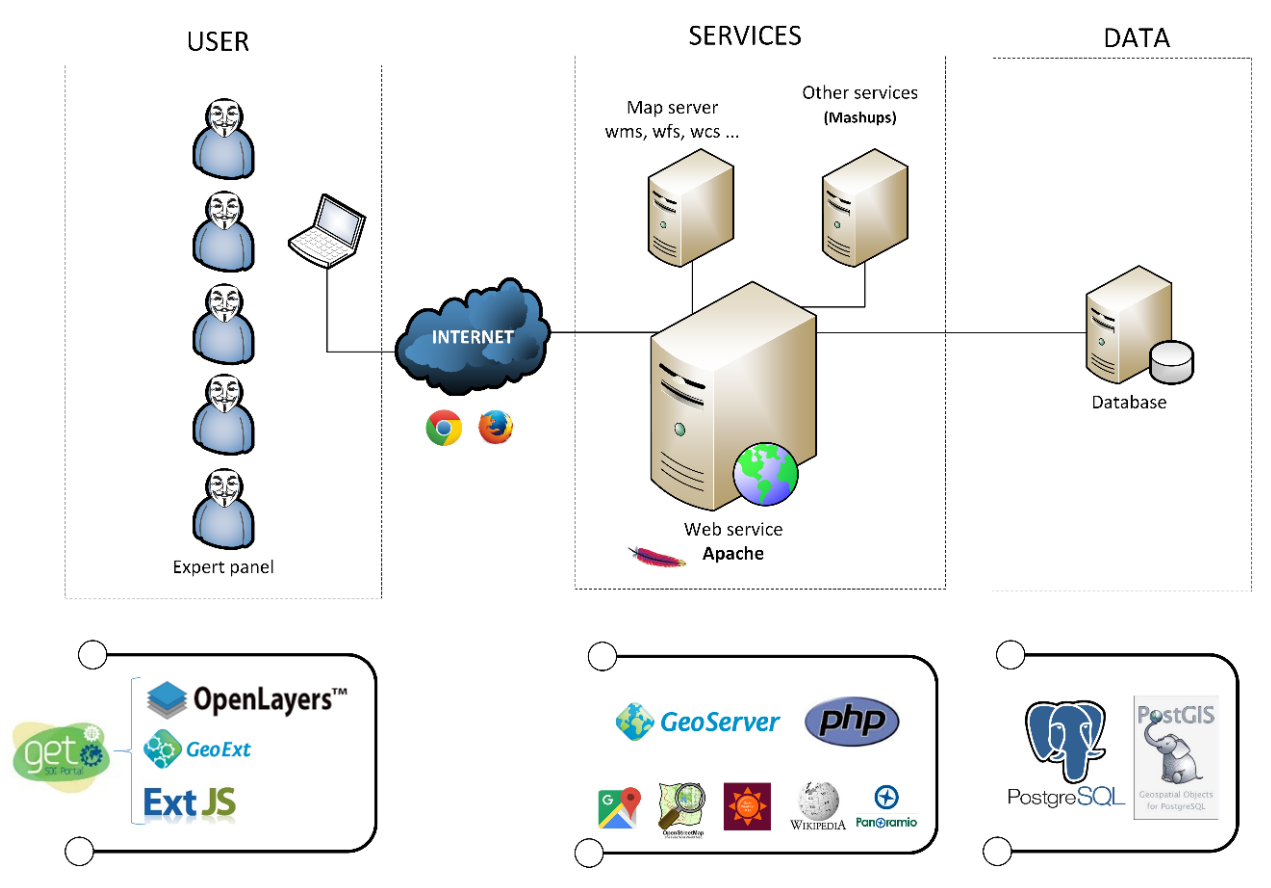

Figure 1. Architecture of Geospatial System of Collective Intelligence (SIGIC). 
Table 1. Updated (2009-2015) of the empirical PPGIS/PGIS studies for mapping ecosystem services from Greg Brown and Fagerholm [9] up to 1 December 2015.

\begin{tabular}{|c|c|c|c|c|c|c|c|c|c|}
\hline Study Year & Location & $\begin{array}{l}\text { Ecosystem } \\
\text { Services } \\
\text { Mapped }\end{array}$ & $\begin{array}{l}\text { Participatory } \\
\text { Mapping } \\
\text { Technology }\end{array}$ & $\begin{array}{l}\text { Spatial } \\
\text { Mapping } \\
\text { Method }\end{array}$ & Map Scale & $\begin{array}{l}\text { Sampling Method, } \\
\text { Participants, Data } \\
\text { Collection Method }\end{array}$ & Spatial Analyses & $\begin{array}{l}\text { Published } \\
\text { References }\end{array}$ & $\begin{array}{l}\text { Contribution to Advancing } \\
\text { PPGIS/PGIS Practice }\end{array}$ \\
\hline 2013 & Sydney, AU & $\begin{array}{l}\text { Landscape } \\
\text { services }\end{array}$ & $\begin{array}{l}\text { Digital } \\
\text { Internet } \\
\text { Google Maps }\end{array}$ & Points, lines & $\begin{array}{l}(\text { Zoom level }=12) \\
1: 72,000 \text { several } \\
\text { spatial scales }\end{array}$ & $\begin{array}{l}\text { Survey online and in } \\
\text { the field, GPS } \\
\text { tracking }(n=516)\end{array}$ & $\begin{array}{l}\text { Compared frequency data, such as the } \\
\text { socio-demographics and rider } \\
\text { characteristics, Pearson's chi-square } \\
\text { tests were applied. The rating-scale data } \\
\text { were analysed with analysis of variance } \\
\text { (ANOVA), including skill level and } \\
\text { sampling mode (field vs. online). } \\
\text { Open-ended questions were analszed } \\
\text { qualitatively by identifying the major } \\
\text { categories/themes emerging from } \\
\text { participant's comments }\end{array}$ & [21] & $\begin{array}{l}\text { Decision support: allowing park } \\
\text { agencies to prioritize future } \\
\text { visitor management actions }\end{array}$ \\
\hline 2012 & $\begin{array}{l}\text { Southern } \\
\text { Suriname }\end{array}$ & $\begin{array}{l}\text { Landscape } \\
\text { services }\end{array}$ & $\begin{array}{l}\text { Cartographical } \\
\text { maps }\end{array}$ & Polygons & $\begin{array}{l}\text { Varied from } \\
1: 100,000 \text { to } \\
\text { 1:250,000. Base } \\
\text { map with DEM } \\
\text { (size A1) }\end{array}$ & $\begin{array}{l}\text { Workshops with } \\
\text { indigenous } \\
\text { communities } \\
(n=191)\end{array}$ & $\begin{array}{l}\text { Identified high concentrations of values } \\
\text { that defined as service provisioning } \\
\text { hotspots (SPH) by applying a cut-off } \\
\text { value equal to the upper third of the } \\
\text { polygon density distribution }\end{array}$ & [22] & $\begin{array}{l}\text { Feasibility: identifying } \\
\text { conservation areas necessary to } \\
\text { safeguard the provision of } \\
\text { important ecosystem services for } \\
\text { indigenous communities }\end{array}$ \\
\hline $\mathrm{N} / \mathrm{d}$ & $\begin{array}{l}\text { Hypothetical } \\
\text { study area. } \\
\text { Northern Ohio } \\
\text { along the western } \\
\text { Lake Erie, USA }\end{array}$ & $\begin{array}{l}\text { Landscape } \\
\text { values typology }\end{array}$ & $\begin{array}{l}\text { Digital } \\
\text { Internet } \\
\text { Google Maps }\end{array}$ & $\begin{array}{l}\text { Predefined } \\
\text { polygons on } \\
\text { a map }\end{array}$ & $($ Zoom level = 12) & $\begin{array}{l}\text { Method or Borda } \\
\text { Count, survey } \\
(n=21)\end{array}$ & $\begin{array}{l}\text { Multi-Criteria Decision Analysis } \\
\text { (MCDA) to attain consensus with the } \\
\text { Borda method }\end{array}$ & [3] & $\begin{array}{l}\text { Decision support: } \\
\text { Evaluation of alternatives } \\
\text { for wind farm selection }\end{array}$ \\
\hline 2010 and $2004^{1}$ & $\begin{array}{l}\text { Kangaroo Island, } \\
\mathrm{AU}\end{array}$ & $\begin{array}{l}\text { Landscape } \\
\text { services }\end{array}$ & $\begin{array}{l}\text { Digital } \\
\text { Internet } \\
\text { Google Maps }\end{array}$ & Points & $($ Zoom level = 12) & $\begin{array}{l}\text { Random survey } \\
(n=86)\end{array}$ & $\begin{array}{l}\text { Compare the spatial distributions of } \\
\text { markers placed by respondents by using } \\
\text { kernel density "hotspot" analysis and } \\
\text { the phi-coefficient }(\varphi) \text { statistics to } \\
\text { measure the strength of the relationship } \\
\text { (explanation following) }\end{array}$ & [23] & $\begin{array}{l}\text { Feasibility: identifying and } \\
\text { monitoring regional tourism } \\
\text { development preferences }\end{array}$ \\
\hline 2007-2008 & Meinong, TW & $\begin{array}{l}\text { Landscape } \\
\text { values typology }\end{array}$ & $\begin{array}{l}\text { Digital } \\
\text { Internet } \\
\text { Google Earth }\end{array}$ & Points & $\begin{array}{l}\text { Different } \\
\text { zoom level }\end{array}$ & $\begin{array}{l}\text { Workshops } \\
(n=25)\end{array}$ & $\begin{array}{l}\text { Continuous discussion to attain } \\
\text { a delimitation of consensus points }\end{array}$ & [2] & $\begin{array}{l}\text { Data quality: analyse how the } \\
\text { processes and outcomes of the } \\
\text { PPGIS can make an impact on } \\
\text { empowerment }\end{array}$ \\
\hline 2011 & $\begin{array}{l}\text { Otago and } \\
\text { Southland, NZ }\end{array}$ & $\begin{array}{l}\text { Landscape } \\
\text { values typology }\end{array}$ & $\begin{array}{l}\text { Digital } \\
\text { Internet } \\
\text { Google Maps }\end{array}$ & Points & $\begin{array}{l}(\text { Zoom level = 12) } \\
\text { 1:100,000 }\end{array}$ & $\begin{array}{l}\text { Survey recruited } \\
\text { through a random } \\
\text { mail, newspapers, } \\
\text { and visitor contact } \\
(n=260)\end{array}$ & $\begin{array}{l}\text { Benchmarking PPGIS native vegetation } \\
\text { classification against the expected native } \\
\text { values, } 1000 \text { random points within the } \\
\text { two regions were identified using } \\
\text { stratified sampling based on the } \\
\text { proportion of native vegetation markers } \\
\text { placed in each region }\end{array}$ & [24] & $\begin{array}{l}\text { Data quality: assesses the spatial } \\
\text { accuracy of PPGIS data collected }\end{array}$ \\
\hline 2009 & $\begin{array}{l}\text { Garstang, } \\
\text { Lancashire, UK }\end{array}$ & $\begin{array}{l}\text { Landscape } \\
\text { typology }\end{array}$ & $\begin{array}{l}\text { Digital } \\
\text { Internet } \\
\text { Google Maps }\end{array}$ & $\begin{array}{l}\text { Polygons } \\
\text { (spray } \\
\text { patterns) }\end{array}$ & $\begin{array}{l}\text { Several spatial } \\
\text { scales }\end{array}$ & $\begin{array}{l}\text { Survey recruited } \\
\text { through a random } \\
\text { mail }(n=33)\end{array}$ & $\begin{array}{l}\text { Initial patterns in the data may } \\
\text { be revealed through simple } \\
\text { density analysis }\end{array}$ & [25] & $\begin{array}{l}\text { Data quality: create spatial } \\
\text { representations on a map using } \\
\text { a familiar airbrush-style interface }\end{array}$ \\
\hline
\end{tabular}

${ }^{1}$ Is shown in the table of Greg Brown \& Fagerholm [9] (p. 123). 
Model [7] was followed in order to create the Real-Time Spatial Delphi method [26]. This application, named Geospatial System of Collective Intelligence (SIGIC after its acronym in Spanish), was used to allow a panel of experts to provide their opinions in an anonymous, distributed, and asynchronous real-time way to answer a spatial survey, in which each question requires an answer or specific opinion reflected in a map with given limits. Just as it is done in other types of surveys, and by assuming an isotropy in a bi-dimensional space [15], such limits are represented by the shape of a circle with a different color for each question in the survey. Note that the questions are not "classical" questions like in any classical questionnaire. The answers are in the form of placing a point on a map.

\subsection{Methods}

Each spatial answer is complemented by a short argument in text, and each circle also serves the experts as an indication of the limits of the map in regard to the area of the convergence of their opinions or geo-consensus, which comprises at least $50 \%$ of all points coming from the answers or opinions by the panel according to Di Zio and Pacinelli [15], "the classical Delphi provides the first and third quartile calculation to define a range containing $50 \%$ of the evaluations of the panel (in the case of frequency distribution, the interquartile range includes $50 \%$ of the values of the distribution)". Also, because it is a real time application, as the survey is being answered or modified, the circumference usually changes its size too, with the understanding that the smaller the size of the circle, the higher the degree of spatial consensus (geo-consensus), and vice versa.

It should be mentioned that, by following the Real Time Delphi procedure [19,27], the respondents participate in a given time period, always anonymously, and they can change their answers as many times as they want, but every change will invalidate the previous answer. Consequently, only the latest changes in each question are considered because each participant can only provide one answer per question. In addition, in order to promote controlled feedback and the convergence of opinions, they can observe their own answers and the updated answers from the others. Thus, the participants are informed in real time throughout the exercise process and of when the final result of the exercise is obtained as well. It is also worth mentioning that each participant can include some digital documents such as pictures, videos, texts, etc., for the same purpose.

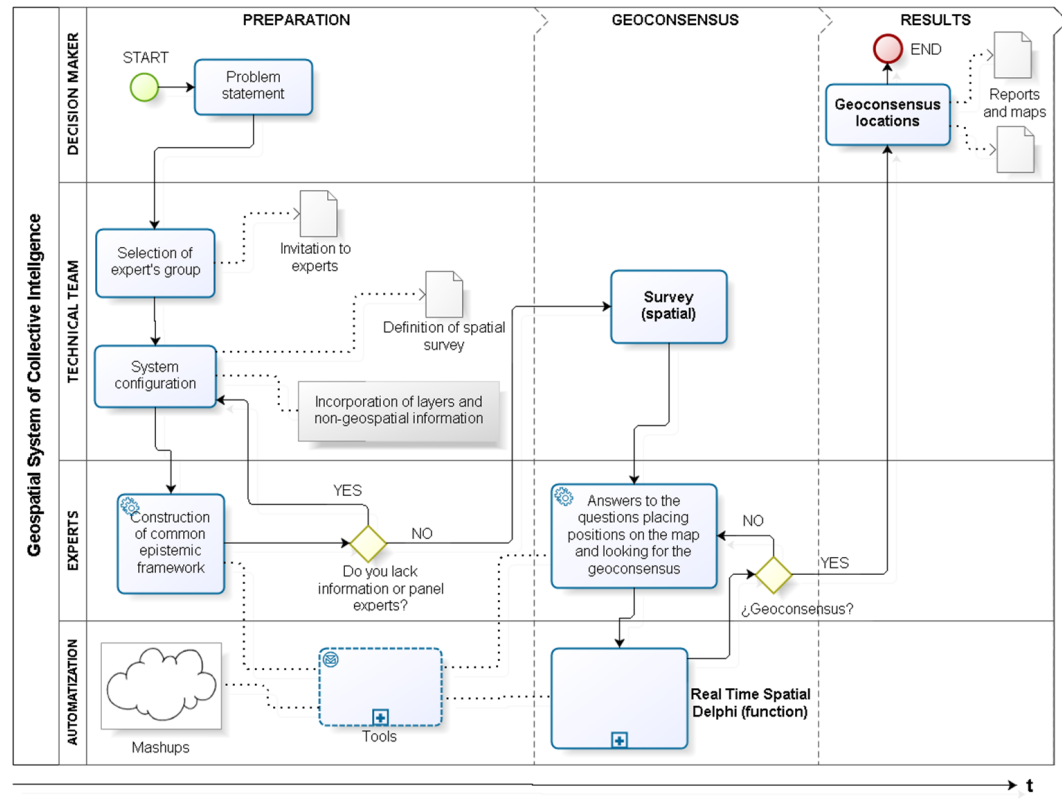

Figure 2. Scheme of the methodological process (elaborated by the authors).

This application, mostly developed based on the open source software GET SDI Portal [28], is multilingual, compatible with the formats for geospatial data based on the ISO/OGC norms, 
and incorporates various tools and user-friendly services based on free APIs such as Twitter, Wikipedia, Openweathermap, and Google Maps, among others. This is additional to the well-known functions for the manipulation of a map's view (i.e. zoom, pan, distance, and so on).

In order to provide a broad overview of the general workflow, as well as to describe the functions as a whole for the proper description of the system implemented, in Figure 2 we present the context diagram that illustrates the overall method of the Geospatial System of Collective Intelligence. The three main phases that compose it can be observed (preparation, geo-consensus, and results), as well as the four cardinal groups of participation (decision-makers, technical equipment, experts, and automations), the basic tasks and processes, and the logical sequence flow and main interconnections between all of them.

\section{Results}

\subsection{Case 1: Location of Places for Installation of Mobile Blood-Collection Units}

It is a well-known fact that blood is a vital liquid to human life as well as a much-needed commodity in various medical treatments, even more so if it is required for cases of surgeries and medical emergencies. Therefore, the security and integrity of the blood supply has come to be considered by the International Federation of Red Cross and Red Crescent Societies as fundamental to the health system safety of each country [29].

Each year, several public and private organisations around the world promote blood-collection campaigns in order to obtain this liquid through voluntary contributions from donors. Since it is impossible to manufacture or acquire it by any other means, its supply remains closely related to the corresponding number of donors. Hence, it is necessary to focus efforts in providing enough judgment elements to allow faster decision-making processes both in planning these campaigns, as well as in their logistics and operation. The territorial aspects in both cases, though, must be considered as a determinant factor $[30,31]$.

Thanks to the initiative of the National Blood Program of the Ministry of Public Health of Ecuador, and seeking to increase the number of blood donors for the 2016 blood drive campaign, compared to this year's, an exercise was conducted to locate, through the judgment of various social actors, four strategic locations for the installation of a mobile blood-collection unit.

In this way, a multidisciplinary team was formed with 17 representatives from the academic sector, public administration, and civil organisation, all with expertise in the operation and logistics of blood-collection campaigns and/or public health. With the support of this team (hereafter called 2the panel of experts"), an exercise was created in order to determine the location of four strategic points for the mobile blood-collection day of 2016, to be held in the city of Santa Ana de los Ríos de Cuenca, Ecuador, which has a population of about 500,000 inhabitants, according to official data. It is noteworthy that, of the 17 experts referred to, none had experience in the use of geographic information systems and digital mapping.

Once registered in the system, each expert was provided with login credentials (username and password), a guide for system operation, and necessary contacts in case they needed some support, leaving the expert panel duly set. Those who participated did so in an anonymous, asynchronous, and distributed exercise during 22 calendar days (18 September to 9 October 2015), answering a survey spatially (and literally) composed of 5 questions. Four of these questions required the participants to identify, in order of importance, the donor turnout volume and the places to make the blood-collection, whereas the fifth one served to demand the assignment of an extra place in case they considered it necessary.

To that end, and in order to support the opinion of the experts, in the system were included the geospatial layers of population census tracts classified into three categories (less than 3000 inhabitants, between 3000 and 5000 inhabitants, and more than 5000 inhabitants), as well as hospital centers (of first and second level) and other important public buildings in the city (sports fields, educational buildings, 
religious temples, parks and plazas, malls, and gas stations), all of them provided by the Ministry of Health. Similarly, two initial documents were added as non-georeferenced documentary information, and during the experimentation seven more documents were added.

As an initial reference and in order to establish spatial limits to the survey (as is analogously done in other survey types), a circle of $8 \mathrm{~km}$ in diameter was placed on the map, the center of which corresponds approximately to the geometric center of the city of Santa Ana de los Ríos de Cuenca, Ecuador, covering with this circumference almost the whole city. After 22 days of the exercise, the identification of four places to carry out the blood-collection campaign was determined through the convergence of the spatial opinions coming from most of the experts (geo-consensus). Note that a fifth place was also identified by consensus, but only of six experts of the panel.

In Figure 3, each graph shows the spatial evolution of the geo-consensus, determined by the diameter of the circle, which indicates the portion of territory containing at least $50 \%$ of an expert's spatial opinions regarding the chosen sites. As a result of this, the qualitative assessment shows a smaller diameter that indicates a greater consensus and vice versa. In the y-axis, the time is represented from the beginning of the exercise until the conclusion. Notice that starting at the 10th, it gradually achieves a greater consensus on the location of places, which was due to the greater participation of the experts, as can be seen through the interpolation curve that shows the reduction of each circle during the course of the 22 days of the exercise.
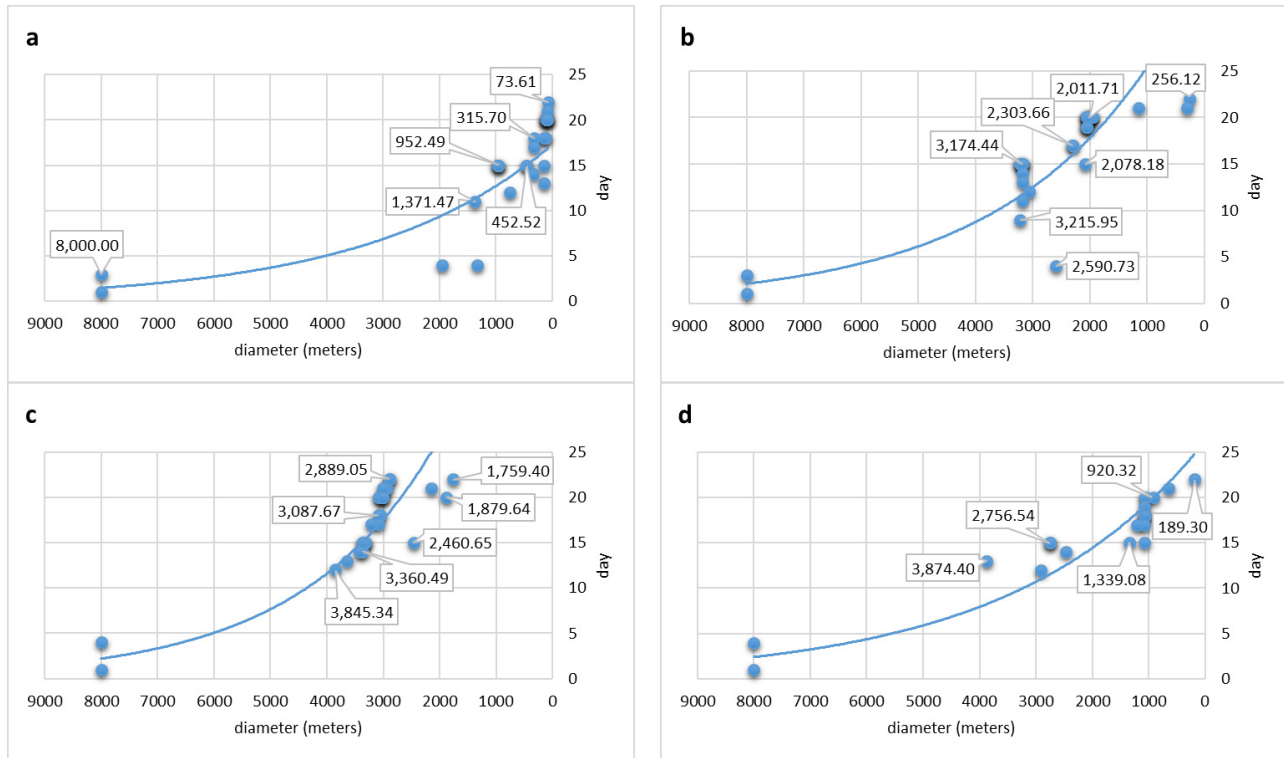

Figure 3. Spatiotemporal evolution of the geo-consensus on questions 1 (a); 2 (b); 3 (c) and 4 (d). Location of places for installation of mobile blood-collection units.

On the other hand, in Figure 4, part of the user interface system is shown, with the panel survey (with the questions in Spanish) and the map with the final geo-consensus areas corresponding to each of the four questions mentioned previously. In the upper left corner of the map can be seen the answers to question 1 in blue, the diameter of which corresponds to $90.77 \mathrm{~m}$ on the ground, and the answers to question 4 in pink, with a diameter of $189.30 \mathrm{~m}$. In the lower right quadrant, the answers to question 2 are in yellow, with a diameter of $256.12 \mathrm{~m}$, and the answers to question 3, with a circle of $1.76 \mathrm{~km}$ in diameter, are in green. The arguments window for question 3 is also shown, in which you can see the justification comments of two expert panelists (in Spanish). The date and time of each response are shown too, as well as whether it belongs or not to the geo-consensus (in green and red, respectively). Finally, the diameter and area of the corresponding circle when each user stated their opinion are also shown. 


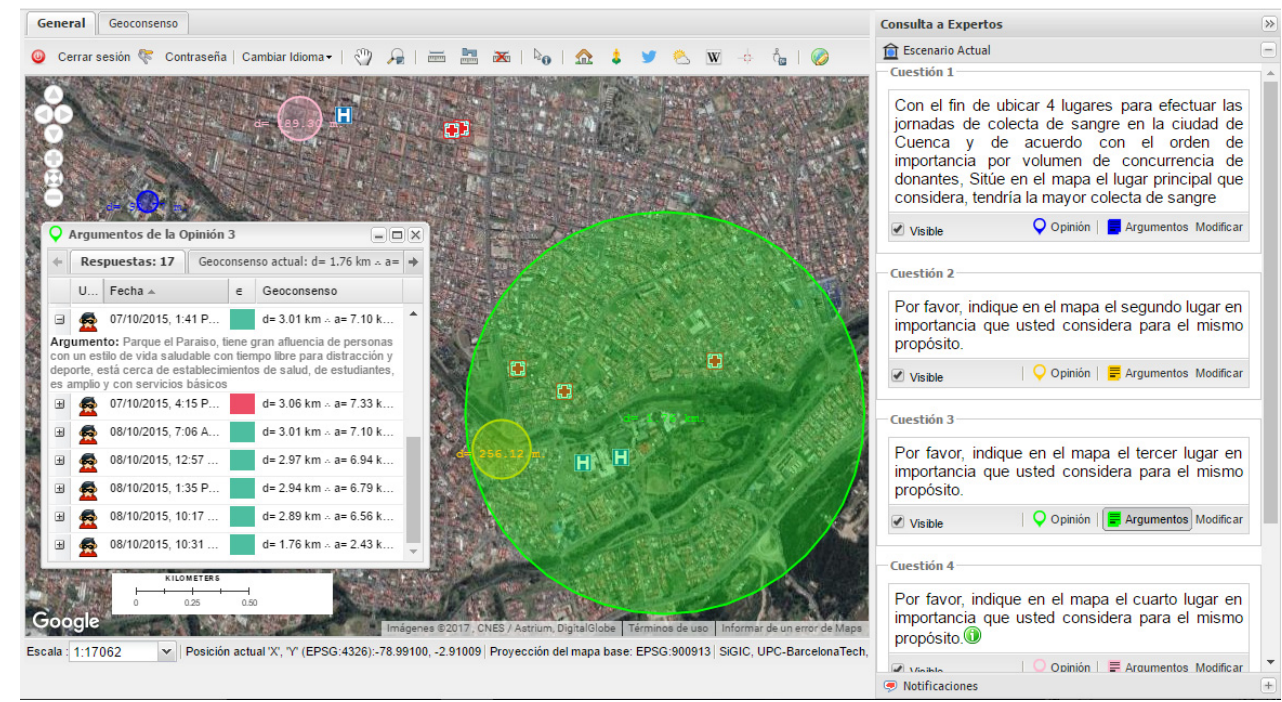

Figure 4. Map with circles corresponding to the final geo-consensus of questions 1-4.

In Figure 5, each graph shows the evolution of the geo-consensus derived from the participation of 6 experts of the panel, who considered the need to establish one more mobile unit for blood-collection, in addition to the others. Hereafter, comes the general geo-consensus chart, in which the moments of the exercise with higher and lower activity of the experts can be viewed, among other features.
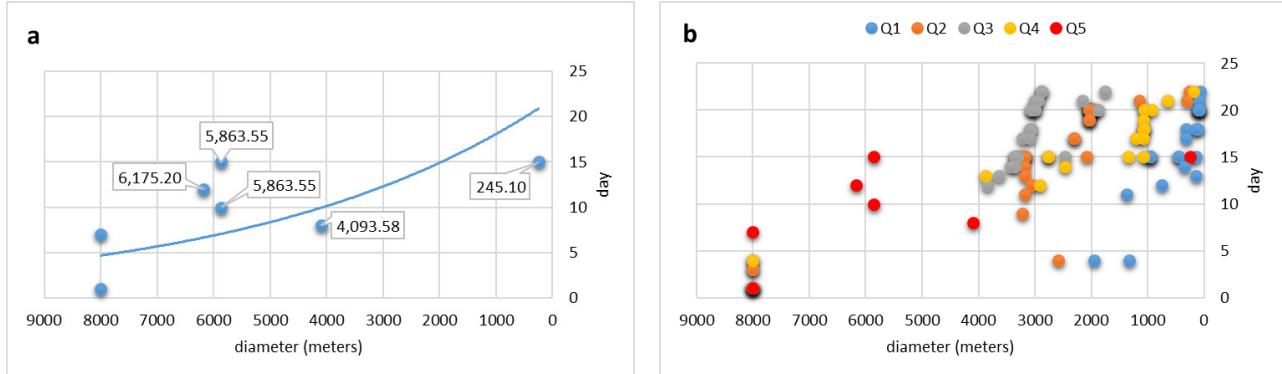

Figure 5. Spatiotemporal evolution of the geo-consensus on question 5 (a); and the geo-consensus related to the whole exercise $(\mathbf{b})$.

\subsection{Case 2: Zoning of Street Prostitution}

In general terms, zoning is a complex process through which a state intervenes to regulate the land use of territorial divisions in order to control its activities, keep order, and preserve the well-being and sustainability of its inhabitants. Certainly, and to find the best alternatives for such cases, it is ever more evident to take into consideration the participation of the diverse social stakeholders involved. Consequently, being able "to democratise" the selection of the most convenient location for a given purpose during the decision-making process can represent a significant contribution [2].

Nowadays, there is no doubt that a social aspect requiring immediate attention in terms of zoning is street prostitution, which not being illegal in certain cities of the globe, as in the Italian case [32], tends to proliferate and turns into a bigger public health problem, among other negative aspects. Because of this, in this section, a case study is presented which aimed to identify suitable locations from the point of view of varied social stakeholders for the zoning of street prostitution in the municipalities of Silvi, Città Sant' Angelo, Montesilvano, Pescara, and Francavilla Al Mare of the Abruzzo region in Italy, which, because of its geographical location in middle of the Italian peninsula, facing the Adriatic 
sea, is a major pole of attraction for immigrants from West Africa and Eastern Europe, which are key regions along the sexual trade routes in the region [33,34].

In this study, nine representatives from the government, academia, and social organisations took part and made up the panel of experts who, through the system, answered in an anonymous, asynchronous, and distributed way a spatial survey consisting of 5 questions (one for each of the abovementioned municipalities). These questions required answers in order to indicate on a map the suitable locations for the zoning of street prostitution in each of the municipalities, and also asked the participants to justify via a short text message the selection of their location in an effort to promote feedback and the convergence of opinions among everyone on the panel of experts.

It should be mentioned though, that the support given to the experts consisted only of the addition of one layer of geospatial information in the system, which showed the administrative division of the five municipalities in the study, which was carried out across 34 calendar days that included the summer holidays period (7 August/9 September 2015).

As an initial reference, and in order to establish the spatial limits of the survey (as analogously done for other types of surveys), a concentric circle in each of the municipalities was placed according to its territorial expansion (Silvi $8.9 \mathrm{~km}$, Città Sant' Angelo $14.4 \mathrm{~km}$, Montesilvano $7.26 \mathrm{~km}$, Pescara $10.6 \mathrm{~km}$, and Francavilla Al Mare $8.78 \mathrm{~km}$ ), so each municipality was represented with a different diameter.

At the end of the 34 days of the study, and through the convergence of the spatial opinions of the majority of the experts (geo-consensus), three suitable locations for the zoning of street prostitution could be identified, which corresponded to four of the municipalities in the stud. Oone of the locations could be common to the municipalities of Silvi and Città Sant' Angelo. However, it was not possible to precisely determine a suitable location in the municipality of Francavilla Al Mare.

The process of geo-consensus can be seen in Figure 6. Please note how the dimensions of the geo-consensuses in the graphs of questions 2,3, and 4 show on their own well delimited areas, whereas the extension of the geo-consensuses related to questions 1 and 5 entail non-defined aspects. Due to this, the extension of about two kilometers that they represent allows for multiple options. Nevertheless, the visual analysis of the areas of geo-consensus represented on the map can suggest for questions 1 and 2 the possible intersection of a same surface, the dimension of which is of a considerable magnitude (Figure 7) but which can be supported through a study of the arguments for both questions given by the experts.
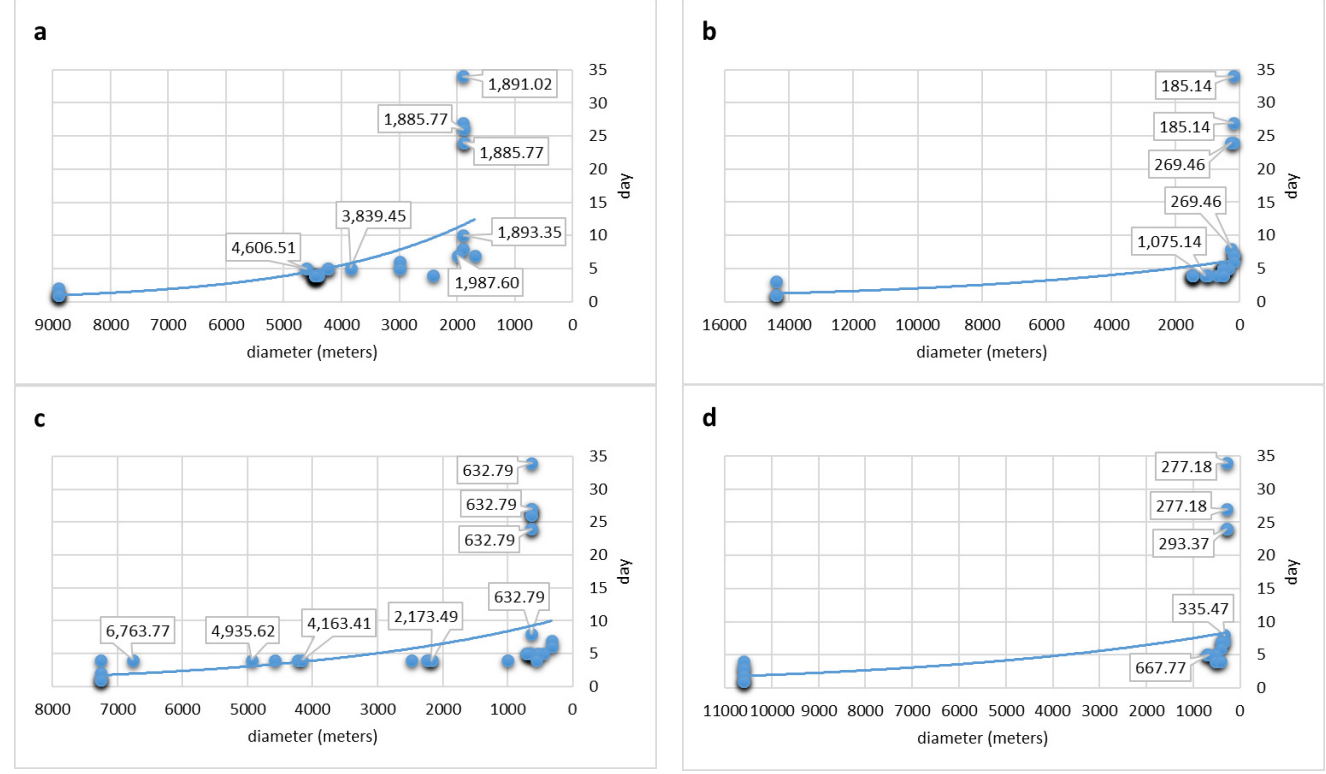

Figure 6. Cont. 


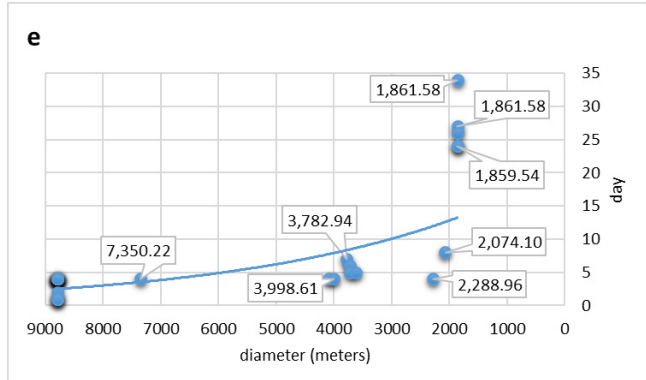

Figure 6. Spatiotemporal evolution of the geo-consensuses related to determining the locations for the zoning of street prostitution. Questions 1 (a); 2 (b); 3 (c); 4 (d) and 5 (e).

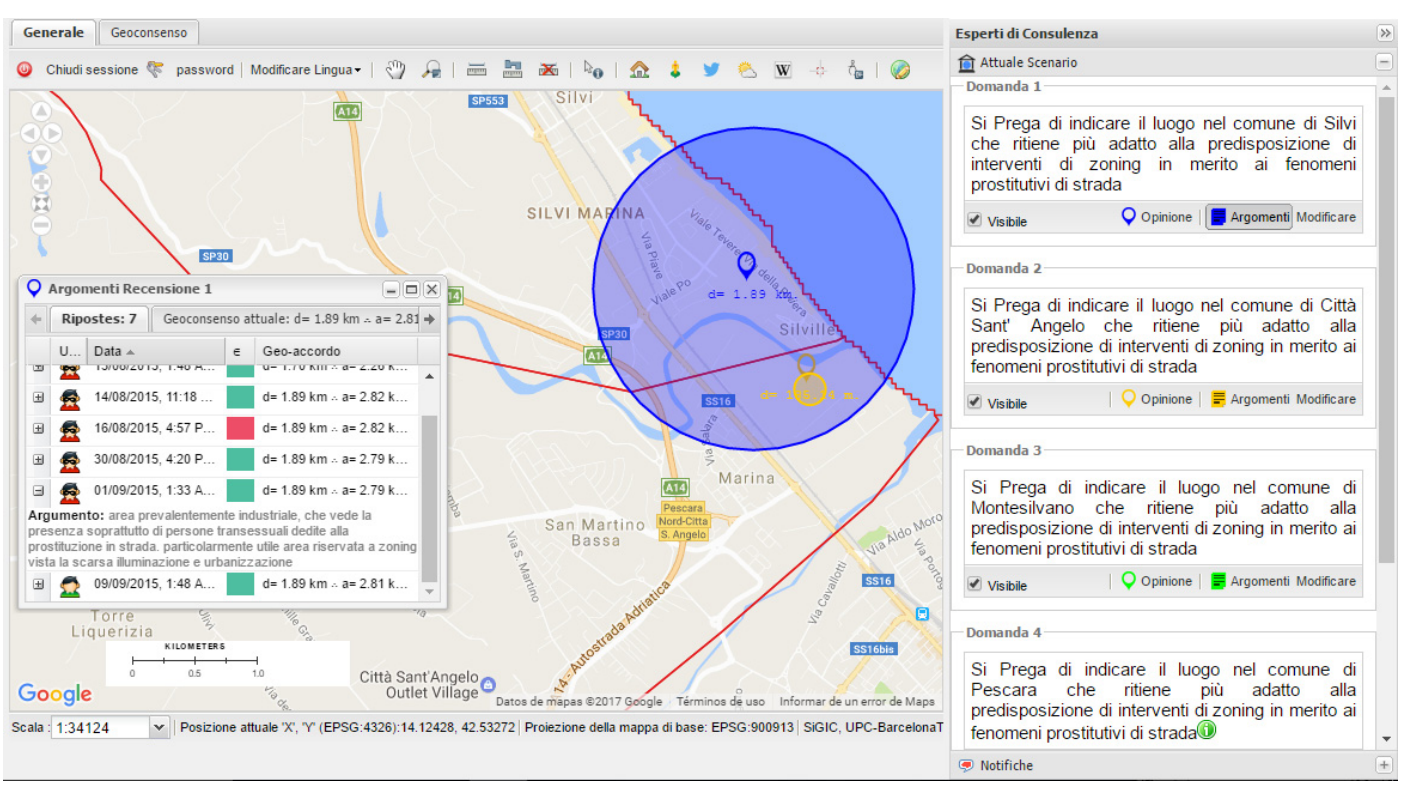

Figure 7. Specific case concerning the potential intersection of the locations corresponding to questions 1 and 2 for the municipalities of Silvi and Città Sant' Angelo.

\section{Discussion and Conclusions}

A review of the literature shows that, in most cases, the data collection is carried out and local experience is first taken into consideration through P/PGIS. Then this information is used during the spatial analysis for the decision-making process, so it is necessary to focus efforts on developing mechanisms that allow the direct participation of the stakeholders during this process through the selection of alternatives via consensus and not only based on opinions about their preferences.

It becomes evident that these practices are more and more needed, given that the decision-making process for the purpose of planning and adoption of territorial policies is a complex one that requires the best alternatives from all possible perspectives, especially the participation and consensus of the involved stakeholders [1-3].

Concerning the studies that already provide mechanisms that allow involved stakeholders to participate in P/PGIS during the decision-making process through a Collective Spatial Analysis based on consensus, one can mention those proposed by Mekonnen and Gorsevski [3] and Tsai et al. [2], which represent the most significant achievements in this regard. However, it should be considered that, in the first case, the focus was based on locations dependent on the previous selection of characteristics and places to evaluate, so a potential selection outside those alternatives was not considered, which could be seen as a restriction to participants. Moreover, and regarding the interface of their model, albeit one 
of simple operation, the required information must be provided by people with a certain specialization and mastery of the subject, at least as far as the estimated variables are concerned.

Regarding the second proposal, we consider that, for certain cases, confrontation of the different actors may not be the best way to approach decision-making due to potential conflicts among parties or a larger influence being exerted by one of them. This is in addition to the execution times, which are significant in regard to other available methods.

Thus, this article intends to contribute to the knowledge leading to the solution of the inconveniences previously mentioned, given that the method presented here allows for a collaborative work in a simple, interactive, asynchronous, real-time, and distributed way, promoting at all times the free selection of locations by the participants through spatial consensus in an anonymous way, which will always display the preference of the majority delivering controlled feedback.

In addition, it is important to note that, in this proposal, the participants can provide additional information and modify their answers as many times as it is considered convenient throughout the duration of the exercise, which is new in the practice of P/PGIS, thereby generating and stimulating the Collective Spatial Analysis. In light of the aforementioned, and although this approach is still in a subjective and initial stage, it does drive improvements in the collection and integration of knowledge and local experience, amongst which is an interdisciplinary and consensual contribution.

The case studies presented in this paper were respectively proposed to the authors by the Ministry of Public Health of Ecuador, and a non-profit youth empowerment organisation working in collaboration with the University of Chieti-Pescara, Italy, with the goal of having experts from different disciplines contributing to the decision-making process regarding the selection of the most appropriate sites for each case.

For this research these case studies allowed the evaluation of the possibility of constituting a Collective Spatial Analysis and of the implementation of the SIGIC as a tool to foster a geo-consensus, since both depict aspects of spatial decision-making in planning different realities of geographical complexity, such as public health (site location for an annual blood collection campaign) and land-use planning (zoning of street prostitution). However, it is common that in such aspects the intervention of different social actors is necessary for the selection of the best alternative, preferably in a consensual way, which was possible to obtain in such cases through the methodology displayed here.

Thanks to this approach, multidisciplinary groups without experience in the use of geo-technologies were able to interact, study and, determine the locations of greater convenience from their different perspectives and interests through the consensus of their spatial opinions, thereby facilitating the decision-making process.

It should also be considered that the tool presented here is an archetype that is based on a Spatial Decision Support System (SDSS), and, like any other decision support system, this does not generate an ultimate solution, but only contributes, together with other elements, to the choice of the most suitable alternatives.

It can be said that a Collective Spatial Analysis is feasible if it is understood as the situation in which a group (through its conclusions, assumptions, or solutions) studies, reflects, and responds to questions that help to determine useful locations to explore, explain, or predict the characteristics or properties necessary for decision-making, taking the complexity of the geographic space in account.

This represents an important advantage over the standard Spatial Analysis, especially in those situations where there is little data to perform geo-processing, in circumstances that are characterised by uncertainty, nonlinearity, emergency, and surprise, or even as a support to limit, guide, verify, and/or correct the results of other spatial analysis alternatives.

The contribution of this research to society can be directly justified, since the decisions to locate services and infrastructure, for instance, would not be invariably taken from the judgment of one single stance but rather determined through various social agents, who along with their background and experience, provide their opinions to reach a geo-consensus. Thus, more democratic solutions are brought forward, and in this way the gap between everyone's varied interests is reduced. 
In that regard, this system is being tested in different areas of the world and for different topics. To date, here are the surveys that have been carried out:

- Location of monitoring sites for HIV screening tests for pregnant women (Esmeraldas, Ecuador);

- Environmental planning and management at a scientific station (Pedro Vicente Maldonado, Ecuador);

- Strategic Environmental Assessment of wind energy (Mexico);

- Location of an air quality monitoring station (Pescara, Italy).

In this way, the approach presented here can be a starting point to establish new goals and objectives for research regarding the support of spatial decision-making through a Collective Spatial Analysis.

As an example, the following research questions are suggested. How should Collective Spatial Analysis in a supervised remote sensing classification for multidisciplinary groups of experts be used to determine the set of classes (training areas)? Is it possible to apply Collective Spatial Analysis to locate some good, service, or event by geo-consensus with the participation of groups called openly through the main social networks? Could the quality of the data in the cartographic production area be improved by means of Collective Spatial Analysis? What results would be obtained if Collective Spatial Analysis were to be used in conjunction with the determination of dates in order to obtain a prospective spatio-temporal consensus from the criterion of a panel of experts?

Finally, we believe that it would be beneficial to explore the use of this archetype by including it in expert systems; either to incorporate the subjective knowledge of a collective group into such systems or as a way of delimiting and/or correcting automated data models.

Acknowledgments: The authors would like to thank the sub-secretary of the Governance of Public Health and the National Blood Program, the Ecuadorian Ministry of Public Health, and Simone Di Zio of the University of Chieti-Pescara for their support in the realization of this research. They would further like thank their PhD colleague Marco Lino Calderón Saldierna for his valuable collaboration in the development of this work.

Author Contributions: This research was conducted with the initiative and methodological proposal of Juan Daniel Castillo-Rosas, who has also developed the SIGIC platform and has analysed the results of this work with the support and guidance of María Amparo Núñez-Andres and Josep María Monguet-Fierro. José José Diez-Rodríguez assisted with the analysis of results and the drafting of the discussion section and conclusions as well as the editing work. Alex Fernando Jiménez-Vélez materialised the exercise of blood collection and contributed to the interpretation of the results of both cases presented in this paper.

Conflicts of Interest: The authors declare that there are no conflicts of interest.

\section{References}

1. Voss, A.; Denisovich, I.; Gatalsky, P.; Gavouchidis, K.; Klotz, A.; Roeder, S.; Voss, H. Evolution of a participatory GIS. Comput. Environ. Urban Syst. 2004, 28, 635-651. [CrossRef]

2. Tsai, B.-W.; Lu, D.-J.; Chung, M.-K.; Lien, M.-C. Evaluation of PPGIS empowerment-A case study of Meinong Yellow Butterfly Valley in Taiwan. J. Environ. Manag. 2013, 116, 204-212. [CrossRef] [PubMed]

3. Mekonnen, A.D.; Gorsevski, P.V. A web-based participatory GIS (PGIS) for offshore wind farm suitability within Lake Erie, Ohio. Renew. Sustain. Energy Rev. 2015, 41, 162-177. [CrossRef]

4. Perkins, C. Community Mapping. Cartogr. J. 2007, 44, 127-137. [CrossRef]

5. Kingston, R. Public participation in local policy decision-making: The role of web-based mapping. Cartogr. J. 2007, 44, 138-144. [CrossRef]

6. IAP2 International Association of Public Participation. Available online: http://www.iap2.org/?page=A4 (accessed on 10 October 2015).

7. Monguet, J.M.; Gutiérrez, A.; Ferruzca, M.; Alatriste, Y.; Martínez, C.; Córdoba, C.; Fernández, J.; Sanguino, T.; Aguilá, J.; Ramírez, M. Vector consensus model. In Organizational Integration of Enterprise Systems and Resources: Advancements and Applications; Business Science Reference (an imprint of IGI Global): Hershey, PA, USA, 2012; pp. 303-317.

8. Nguyen, N.T. Consensus system for solving conflicts in distributed systems. Inf. Sci. 2002, 147, 91-122. [CrossRef] 
9. Brown, G.; Fagerholm, N. Empirical PPGIS/PGIS mapping of ecosystem services: A review and evaluation. Ecosyst. Serv. 2014, 13, 119-133. [CrossRef]

10. Brown, G.; Weber, D.; de Bie, K. Is PPGIS good enough? An empirical evaluation of the quality of PPGIS crowd-sourced spatial data for conservation planning. Land Use Policy 2015, 43, 228-238. [CrossRef]

11. Fischer, M.M.; Getis, A. Handbook of Applied Spatial Analysis. Software Tools, Methods and Applications; Fischer, M.M., Getis, A., Eds.; Springer: Heidelberg, Germany, 2010.

12. Castillo Rosas, J.D.; Núñez Andrés, M.A.; Monguet Fierro, J.M.; Jiménez Vélez, A. Towards a collective spatial analysis: Proposal of a new paradigm for supporting the spatial decision-making from a geoprospective approach. In Proceedings of the 1st International Conference on Geographical Information Systems Theory, Applications and Management (GISTAM), Barcelona, Spain, 18-30 April 2015.

13. Lévy, P. From social computing to reflexive collective intelligence: The IEML research program. Inf. Sci. 2010, 180, 71-94. [CrossRef]

14. Glenn, J.C. Collective intelligence systems and an application by the millennium project for the egyptian academy of scientific research and technology. Technol. Forecast. Soc. Chang. 2013, 97, 7-14. [CrossRef]

15. Di Zio, S.; Pacinelli, A. Opinion convergence in location: A spatial version of the delphi method. Technol. Forecast. Soc. Chang. 2011, 78, 1565-1578. [CrossRef]

16. Di Zio, S. Convergenza di opinioni in ambito territoriale: Proposta di un real time spatial Delphi. In $13^{\circ}$ Conferenza Italiana Utenti ESRI; ESRI Italia: Roma, Italy, 2012; pp. 1-7.

17. Gnatzy, T.; Warth, J.; von der Gracht, H.; Darkow, I.-L. Validating an innovative real-time Delphi approach-A methodological comparison between real-time and conventional Delphi studies. Technol. Forecast. Soc. Chang. 2011, 78, 1681-1694. [CrossRef]

18. Gordon, T.; Pease, A. RT Delphi: An efficient, "round-less" almost real time Delphi method. Technol. Forecast. Soc. Chang. 2006, 73, 321-333. [CrossRef]

19. Gordon, T.J. The real-time Delphi method. In Futures Research Methodology Version 3.0; Glenn, J.C., Gordon, T.J., Eds.; The Millennium Project, American Council for the United Nations University: Washington, DC, USA, 2009; p. 19.

20. Hsieh, C.-H.; Tzeng, F.-M.; Wu, C.-G.; Kao, J.-S.; Lai, Y.-Y. The comparison of online Delphi and real-time Delphi. In Proceedings of the 2011 Technology Management in the Energy Smart World (PICMET), Taoyuan, Taiwan, 31 July-4 August 2011.

21. Wolf, I.D.; Wohlfart, T.; Brown, G.; Bartolomé Lasa, A. The use of public participation GIS (PPGIS) for park visitor management: A case study of mountain biking. Tour. Manag. 2015, 51, 112-130. [CrossRef]

22. Ramirez-Gomez, S.O.I.; Brown, G.; Verweij, P.A.; Boot, R. Participatory mapping to identify indigenous community use zones: Implications for conservation planning in southern Suriname. J. Nat. Conserv. 2016, 29, 69-78. [CrossRef]

23. Brown, G.; Weber, D. Using Public Participation GIS (PPGIS) on the geoweb to monitor tourism development preferences. J. Sustain. Tour. 2013, 21, 192-211. [CrossRef]

24. Brown, G. An empirical evaluation of the spatial accuracy of Public Participation GIS (PPGIS) data. Appl. Geogr. 2012, 34, 289-294. [CrossRef]

25. Huck, J.J.; Whyatt, J.D.; Coulton, P. Spraycan: A PPGIS for capturing imprecise notions of place. Appl. Geogr. 2014, 55, 229-237. [CrossRef]

26. Di Zio, S.; Castillo-Rosas, J.D.; Lamelza, L. Real Time Spatial Delphi: Fast convergence of experts' opinions on the territory. Technol. Forecast. Soc. Chang. 2017, 115, 143-154. [CrossRef]

27. TMP. The Millennium Project. Available online: http://www.millennium-project.org/millennium/RTDgeneral.html (accessed on 15 August 2015).

28. GET Geospatial Enabling Technologies \& MaP Ltd. Available online: http://www.getmap.gr/v2/eng/ index.php?option=com_content\&task=view\&id=255\&Itemid=554 (accessed on 8 September 2015).

29. IFRC. The International Federation of Red Cross and Red Crescent Societies. Available online: http:/ /www.ifrc.org/ (accessed on 5 October 2015).

30. Halbout, P.; Lebaudy, J.P.; Gagneux, F.; Brosius, N.; Pelletier, B.; Danic, B. La géomatique au service de la collecte de sang. Transfus. Clin. Biol. 2015, 22, 112-126. [CrossRef] [PubMed]

31. Mobasher, A.; Ekici, A.; Özener, O.Ö. Coordinating collection and appointment scheduling operations at the blood donation sites. Comput. Ind. Eng. 2015, 87, 260-266. [CrossRef] 
32. Schmitt, S.; Euchner, E.-M.; Preidel, C. Regulating prostitution and same-sex marriage in Italy and Spain: the interplay of political and societal veto players in two catholic societies. J. Eur. Public Policy 2013, 20, 425-441. [CrossRef]

33. Mancuso, M. Estimating the revenues of sexual exploitation: Applying a new methodology to the Italian context. Glob. Crime 2014, 15, 10-26. [CrossRef]

34. Solivetti, L.M. Old and new criminality: Territory, society and immigration in Italy. In Organized Crime, Corruption and Crime Prevention; Caneppele, S., Calderoni, F., Eds.; Springer International Publishing: Milano, Italy, 2014; pp. 103-114.

(C) 2017 by the authors; licensee MDPI, Basel, Switzerland. This article is an open access article distributed under the terms and conditions of the Creative Commons Attribution (CC BY) license (http:/ / creativecommons.org/licenses/by/4.0/). 